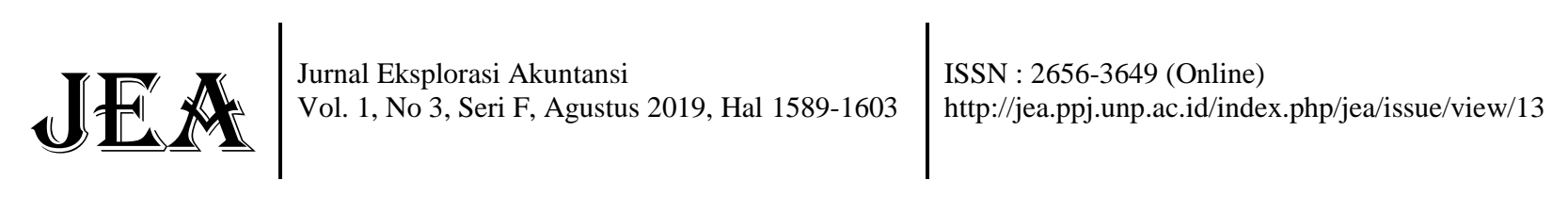

\title{
PENGARUH LOCUS OF CONTROL, TURNOVER INTENTION, KOMITMEN ORGANISASI DAN KECERDASAN EMOSIONAL SPIRITUAL QUOTIENT (ESQ) TERHADAP DYSFUNCTIONAL AUDIT BEHAVIOR
}

\author{
Yulastri Herliza $^{1}$, Mia Angelina Setiawan ${ }^{2}$ \\ 1)Alumni Jurusan Akuntansi Fakultas Ekonomi Universitas Negeri Padang \\ 2)Jurusan Akuntansi Fakultas Ekonomi Universitas Negeri Padang \\ *Korespondensi: yulastriherliza2719@gmail.com
}

\begin{abstract}
Dysfunctional audit behavior is the behavior of auditors in the audit process that is not appropriate or deviates from the standards set. The aim of the study was to determine: (1) the influence of locus of control on dysfuncional audit behavior, (2) the effect of turnover intention on audit behavior dysfuncional, (3) the influence of organizational commitment on dysfuncional audit behavior, (4) the influence of emotional, spiritual, quetiont intelligence (ESQ) against dysfuncional audit behavior.This research was conducted at the Republic of Indonesia BPK Representative auditor West Sumatra Province in 2019. The samples obtained were 44 auditors. The sample collection method uses total sampling technique. The data analysis technique used is multiple linear regression. The results showed (1) locus of control did not affect the dysfunctional audit behavior with a significance value of $0.012<0.05$, (2) turnover intention had a positive effect on dysfunctional audit behavior with a significance value of $0.003<0.05$ (3) organizational commitment had no effect towards dysfunctional audit behavior with a significance value of 0.249> 0.05 and (4) emostional spiritual quotient does not affect the bahaviour dysfunctional audit with a significance value of 0.716>0.05.
\end{abstract}

Keywords: Dysfunctional Audit Behavior; Turnover intention; Organizational Commitment; Emotional Spiritual Quotient(ESQ)

How to cite (APA $6^{\text {th }}$ style)

Herliza, Y., \& Setiawan, M.E. (2019). Pengaruh Locus Of Control, Turnover Intention, Komitmen Organisasi dan Kecerdasan Emosional Spiritual Quotient (Esq) terhadap Dysfuncional Audit Behavior. Jurnal Eksplorasi Akuntansi, 1(3), Seri F, 1589-1603.

\section{PENDAHULUAN}

Tingginya kasus KKN menuntut agar perlunya pengawasan dan sistem pengendalian internal yang lebih baik dalam pelaksanaan pemerintahan dan pengelolaan keuangan Negara. Peran seorang auditor sangat dibutuhkan untuk mengatasi dan mencegah terjadinya KKN. Namun dalam melaksanakan tugasnya, auditor kerap melakukan penyimpangan terhadap nilai-nilai dasar audit yang menyebabkan kualitas laporan hasil audit menjadi kurang dipercaya. Irawati, dkk (2005) menyebutkan bahwa segala bentuk manipulasi atau ketidakjujuran dalam audit akan menimbulkan penyimpangan perilaku dalam audit atau dysfunctional audit behavior. 
Beberapa penelitian terkait bidang audit menunjukkan bahwa penyebab terjadinya dysfunctional audit behaviour adalah karakteristik personal auditor (Donnelly et al, 2003). Karakteristik personal auditor yang memengaruhi dysfunctional audit behaviour secara langsung diantaranya adalah locus of control, turnover intention, dan komitmen organisasi. Harini et al.,. (2010) mengatakan locus of control berbicara tentang cara pandang auditor mengenai keberhasilan dalam pekerjaan mereka dan juga berkaitan dengan penggolongan individu menjadi dua kategori yaitu internal locus of control dan eksternal locus of control. Individu yang memiliki internal locus of control cenderung percaya dan memiliki keyakinan bahwa mereka memiliki kendali atas peristiwa yang terjadi pada dirinya. Sedangkan individu yang memiliki eksternal locus of control yang kuat adalah sebaliknya.

Turnover intention terkait dengan keinginan karyawan untuk berpindah kerja. Turnover intention bisa terjadi karena balas jasa terlalu rendah, mendapatkan pekerjaan yang lebih baik, suasana dan lingkungan pekerjaan yang kurang cocok, kesempatan promosi tidak ada, dan perlakuan yang kurang adil (Hasibuan, 2007:211). Komitmen organisasi adalah suatu perpaduan antara sikap dan perilaku. Komitmen organisasi menyangkut tiga sikap, yaitu rasa mengidentifikasi dengan tujuan organisasi, rasa keterlibatan dengan tujuan organisasi dan rasa kesetiaan pada organisasi (Trisnaningsih, 2003).

Selain karakteristik personal audit, penyebab terjadinya dysfunctional audit behavior adalah adanya pengaruh emotional, spiritual, quotient (ESQ). ESQ berdampak pada dysfunctional audit behavior apabila diantara kecerdasan tersebut berjalan sendiri dan tidak berkesinambungan, sehingga akan mempengaruhi kinerja seorang auditor (Wijayanti, 2012). Penelitian ini mengkombinasikan variabel dependen dan variabel independen dari beberapa jurnal penelitian sebelumnya. Selain itu ketidak konsistenan variabel turnover intention dan komitmen organisasi membuat peneliti tertarik untuk membuktikan adakah pengaruh signifikan atau tidak signifikan terhadap dysfunctional audit behavior.

Berdasarkan latar belakang yang telah penulis uraikan, maka penulis tertarik untuk melakukan penelitian dengan judul "Pengaruh locus of control, turnover intention, komitmen organisasi dan kecerdasan emosional spiritual quotient (ESQ) terhadap dysfuncional audit behavior studi pada auditor Badan Pemerikasa Keuangan (BPK) RI Perwakilan Provinsi Sumatera Barat"

\section{REVIU LITERATUR DAN HIPOTESIS \\ Teori Atribusi}

Teori atribusi merupakan sebuah teori yang menjelaskan tentang bagaimana proses dalam menentukan penyebab perilaku seseorang. Teori atribusi juga menjelaskan bagaimana dalam membuat atau menentukan keputusan tentang prilaku seseorang. Teori atribusi akan mendeskripsikan perilaku seseorang dan mencoba menggali pengetahuan mengapa mereka berperilaku seperti itu (Husna, 2012: 6).

\section{Dysfunctional Audit Behaviour}

Dysfunctional audit behavior merupakan perilaku auditor dalam proses audit yang tidak sesuai atau menyimpang dari standar yang telah ditetapkan. Perilaku ini merupakan reaksi terhadap lingkungan, seperti kurang adanya control. Seorang auditor harus mengikuti standar audit dalam melaksanakan tugasnya. Beberapa dysfunctional audit behavior yang membahayakan kualitas audit secara langsung yaitu altering/replacement of audit procedure,premature sign off, serta underreporting of time. Selain itu perolehan bukti yang kurang akan menyebabkan 
ketidakakuratan dan kesalahan dari tahap audit yang merupakan dampak dari dysfunctional audit behaviour.

\section{Locus of Control}

Teori ini menjelaskan tingkat harapan seorang individu atas hasil dari perilaku yang telah mereka lakukan apakah menggambarkan perilaku mereka sendiri (internal) atau berasal dari luar kendali diri mereka (eksternal). Locus of control tiap individu mampu mencerminkan motivasi yang berbeda dan kinerja yang berbeda. Jadi locus of control merupakan sikap atau cara pandang seseorang dalam menilai keberhasilan dan kemampuannya, apakah dipengaruhi oleh diri sendiri ataupun faktor dari luar dirinya.

\section{Turnover Intention}

Memiliki keinginan untuk berhenti bekerja membuat seseorang menjadi kurang peduli terhadap apa yang ia lakukan di dalam pekerjaan atau organisasinya. Sikap ini dapat mengakibatkan buruknya kinerja karyawan sehingga memungkinkan terjadinya dysfunctional audit behavior.

\section{Komitmen Organisasi}

Komitmen organisasi merupakan sikap terhadap penerimaan tujuan dan nilai suatu organisasi atau instansi. Oleh karena itu, komitmen organisasi yang kuat tercermin dalam sensitifitas yang lebih tinggi atas isu yang melibatkan etika organisasi (Lachman dan Aranya 1986). Adanya komitmen yang tinggi terhadap organisasi yang dimiliki karyawan atau seorang auditor akan membuat mereka merasa lebih peduli terhadap organisasinya, sehingga akan mampu meminimalkan atau mencegah dalam melakukan dysfungsional audit behavior.

\section{Emotional Spiritual Quotient (ESQ)}

Emotional spiritual quotient (ESQ) merupakan sebuah metode pembangunan jiwa yang menggabungkan antara ketiga unsur kecerdasan, yaitu kecerdasan konvensional (IQ), kecerdasan emosional (EQ) dan kecerdasan spiritual (SQ). ESQ berdampak pada perilaku disfungsional apabila di antara kecerdasan tersebut berjalan sendiri dan tidak berkesinambungan, sehingga pada akhirnya akan mempengaruhi kinerja seorang auditor

\section{Pengaruh Locus of Control Terhadap Dysfunctional Audit Behaviour}

Tindakan manipulasi ataupun kecurangan tersebut yang akan menyebabkan dysfunctional audit behavior. Perilaku ini memiliki arti bahwa auditor akan memanipulasi proses auditing untuk mencapai tujuan kinerja. Tindankan pengurangan kualitas auditing bisa ditujukan sebagai pengorbanan yang harus dilakukan auditor untuk bertahan di lingkungan audit. Perilaku ini akan terjadi pada individu yang memiliki locus of control. Peneliti Irawati, dkk (2005) menyatakan bahwa locus of control berpengaruh positif terhadap dysfunctional audit behavior. Hal ini menununjukkan bawa semakin tinggi locus of control individu, semakin mungkin peluang mereka melakukan dysfunctional audit behavior.

H1: Terdapat pengaruh positif antara locus of control terhadap dysfunctional audit behavior.

\section{Keinginan untuk Berhenti Bekerja (Turnover Intention) Terhadap Dysfunctional Audit Behavior}

Auditor yang memiliki keinginan berhenti kerja (turnover intention) lebih berpeluang dalam melakukan dysfungsional audit behaviour karena menurunnya tingkat ketakutan yang ada dalam 
dirinya terhadap sanksi yang didapat bila perilaku tersebut dideteksi. Penelitian yang dilakukan oleh Oktaviani (2017) juga menjelaskan bahwa auditor yang memiliki keinginan untuk berhenti bekerja (turnover intention) cendrung berpengaruh positif terhadap dysfungsional audit behavior. H2 :Turnover intention berngaruh positif terhadap dysfunctional audit behavior.

\section{Pengaruh Komitmen Organisasi terhadap Dysfunctional Audit Behavior}

Komitmen organisasi menunjukkan kekuatan relatif untuk berpihak dan terlibat dalam organisasi, keinginan untuk berusaha sekuat tenaga untuk organisasi, termasuk juga keinginan untuk bertahan dalam organisasi merupakan orientasi individu terhadap organisasi dalam hal loyalitas, identifikasi dan keterlibatan. Tingkat komitmen organisasi yang tinggi akan dikaitkan dengan dysfunctional audit behavior hal ini dilakukan dengan tujuan untuk tetap mempertahankan organisasi tempat mereka bekerja. Penelitian Basudewa dan Merkusiwati (2015) menjelaskan bahwa komitmen organisasi berpengaruh negatif terhadap dysfunctional audit behavior.

H3: Terdapat pengaruh negatif antara komitmen organisasi terhadap dysfunctional audit behavior

\section{Pengaruh Emotional Spiritual Quotient (ESQ) terhadap Dysfunctional Audit Behavior}

Semakin tinggi tingkat ESQ, kemungkinan penerimaan dysfunctional audit bahaviourakan semakin rendah, karena auditor yang memiliki kecerdasan yang tinggi akan lebih berhati-hati dalam melakukan disfungsional auditor, sebab biasanya auditor dapat mempertimbangkan dengan baik setelah dilakukannyanya disfungsional auditor. Hasil penelitian Oktaviani (2017) menyatakan bahwa penerimaan berpengaruh negative terhadap penerimaan dysfunctional audit behavior.

H4: Terdapat pengaruh negatif antara emotional spiritual quotient (ESQ) terhadap dysfunctional audit behavior.

\section{METODE PENELITIAN}

\section{Populasi dan Sampel}

Penelitian ini menggunakan metode kausatif. Populasi dalam penelitian ini adalah 50 orang auditor yang bekerja pada Badan Pemeriksa Keuangan (BPK) RI Perwakilan Provinsi Sumatera Barat. Teknik pengambilan sampel yang digunakan dalam penelitian ini adalah total sampling, dimana jumlah sampel sama dengan populasi (Sugiyono, 2007).

Sumber data yang digunakan adalah data primer berupa kuesioner yang disebarkan kepada para auditor yang bekerja di BPK RI Perwakilan Provinsi Sumatera Barat. Variabel dependen merupakan variabel yang dipengaruhi oleh adanya variabel independen atau variabel bebas. Variabel dependen dalam penelitian ini adalah dysfunctional audit behavior. Variabel independen adalah variabel yang mempengaruhi atau menjadi sebab perubahan sehingga menimbulkan variabel terikat (dependen). Variabel independen dalam penelitian ini adalah locus of control, turnover intention, komtmen organisasi, dan emotional spiritual quotient (ESQ).

\section{Devinisi Operasional \\ Locus Of Control (X1)}

Locus of control menggolongkan individu menjadi dua kategori sebagai berikut: (1) locus of control eksternal, berarti sikap atau perilaku individu sangat tergantung pada kondisi di luar dirinya. (2) locus of control internal, yaitu individu yang percaya bahwa mereka memiliki kendali atas peristiwa yang terjadi pada diri mereka sendiri. Variabel locus of control diukur 
dengan mengembangkan indikator yang dijabarkan melalui 16 item pertanyaan dengan lima poin skala likert yang dikembangkan oleh Oktaviani, W (2017).

\section{Turnover Intention (X2)}

Memiliki keinginan untuk berhenti bekerja (turnoer intention) membuat seseorang menjadi kurang peduli terhadap apa yang ia lakukan di dalam organisasinya. Turnover intention diukur dengan 4 indikator pertanyaan yang diadopsi dari dikembangkan oleh Oktaviani, W (2017).

\section{Komitemen Organisasi}

Komitmen organisasi merupakan sikap kecintaan dan kesetiaan karyawan terhadap organisasinya (Trisnaningsih, 2007). Komitmen organisasi diukur dengan menggunakan instrument yang dikembangkan oleh Basudewa dan Merkusiwati (2015). Instrumen terdiri dari 4 item komitmen organisasi affective dan 6 item komitmen continuance.

\section{Emotional Spiritual Quotient (X4)}

Pada dasarnya manusia diciptakan dengan membawa unsur kecerdasan. Ada tiga model kecerdasan yaitu kecerdasan konvensional (intelegency quotient), kecerdasan emosional (emotional quotient), hingga model kecerdasan ultimat yakni kecerdasan spiritual (spiritual quotient)). Sebagai acuan bagi pengembangan instrumen akan mempergunakan konsep emosional spiritual quotient yang diukur dengan menggunakan instrumen yang dikembangkan oleh Havel, N (2017).

\section{Dysfunctional Audit Behavior (Y)}

Dysfunctional audit behaviour dalam penelitian ini adalah perubahan perilaku auditor yang dapat mengancam suatu sistem audit yang terdiri atas tindakan melaporkan waktu audit dengan total waktu yang lebih pendek dari waktu yang sebenarnya (underreporting of audit time), penyelesaian langkah audit yang terlalu dini tanpa melengkapi keseluruhan prosedur (premature signing-off) serta mengubah prosedur yang telah ditetapkan dalam pelaksanaan audit di lapangan (replacing and altering original aidit procedures).

Dysfunctional audit behaviour menggunakan instrumen yang dikembangkan oleh Donelly et al., (2003) yang diadaptasi oleh Oktaviani, W (2017). Instrumen penelitian ini terbagi ke dalam tiga bagian instrumen yang didesain untuk memperoleh informasi mengenai dysfunctional adit behaviour di lingkungan audit.

\section{HASIL DAN PEMBAHASAN}

Deskripsi Sampel Penelitian

Gambaran umum mengenai profil responden disajikan pada tabel berikut:

Tabel 1. Data Demografi Responden

\begin{tabular}{|c|c|c|c|}
\hline Kriteria & Jenis & Jumlah & Presentase \\
\hline Jenis & Laki-laki & 25 & $56,8 \%$ \\
\hline Kelamin & Perempuan & 19 & $43,2 \%$ \\
\hline & Total & 44 & $100 \%$ \\
\hline
\end{tabular}




\begin{tabular}{|l|l|l|l|}
\hline Umur & $<25$ tahun & 0 & $0 \%$ \\
& $25-35$ & 29 & $65,9 \%$ \\
& tahun & 15 & $34,1 \%$ \\
& $36-45$ & 0 & $0 \%$ \\
& tahun & 44 & $100 \%$ \\
& $>46$ tahun & & \\
& Total & & \\
\hline Pendidikan & S2 & 14 & $31,8 \%$ \\
& S1 & 30 & $68,2 \%$ \\
& D3 & 0 & $0 \%$ \\
& Total & 44 & $100 \%$ \\
\hline Lamanya & $<5$ tahun & 17 & $38,6 \%$ \\
Pengalaman & $5-10$ tahun & 15 & $34,1 \%$ \\
Kerja & $>10$ tahun & 12 & $27,3 \%$ \\
& Total & 44 & $100 \%$ \\
\hline
\end{tabular}

\section{Analisis Statistik Deskriptif}

Gambaran mengenai variabel-variabel penelitian locus of control, turnover intention, komitmen organisasi dan kecerdasan emosional spiritual quotient (ESQ) terhadap dysfunctional audit behavior disajikan dalam tabel descriptive statistics yang menunjukkan angka minimum, maksimum, mean, dan standar deviasi yang dapat dilihat pada tabel berikut ini.

Tabel 2. Statistik Deskriptif

\begin{tabular}{|l|r|r|r|r|r|}
\hline & N & Minimum & Maximum & Mean & $\begin{array}{c}\text { Std. } \\
\text { Deviation }\end{array}$ \\
\hline DAB & 44 & 22 & 48 & 36,45 & 5,728 \\
\hline LOC & 44 & 35 & 63 & 49,66 & 6,111 \\
\hline TI & 44 & 4 & 14 & 10,30 & 2,195 \\
\hline KO & 44 & 24 & 49 & 35,48 & 4,443 \\
\hline ESQ & 44 & 93 & 140 & 108,98 & 9,161 \\
\hline Valid N(listwise) & 44 & & & & \\
\hline
\end{tabular}




\section{Uji Asumsi Klasik}

1. Uji Normalitas

Tabel 3. Uji Normalitas

Uji Normalitas

\begin{tabular}{|c|c|c|}
\hline \multirow{2}{*}{\multicolumn{3}{|c|}{$\begin{array}{c}\text { Uji Normalitas } \\
\text { One-Sample Kolmogorov-Smirnov Test }\end{array}$}} \\
\hline & & \\
\hline & & $\begin{array}{l}\text { Unstandardized } \\
\text { Residual }\end{array}$ \\
\hline \multicolumn{2}{|l|}{$\mathrm{N}$} & 44 \\
\hline \multirow{2}{*}{$\begin{array}{l}\text { Normal } \\
\text { Parameters }{ }^{\mathrm{a}, \mathrm{b}}\end{array}$} & Mean & 0,0000000 \\
\hline & Std. Deviation & 4,83936665 \\
\hline \multirow{3}{*}{$\begin{array}{l}\text { Most Extreme } \\
\text { Differences }\end{array}$} & Absolute & 0,065 \\
\hline & Positive & 0,065 \\
\hline & Negative & $-0,060$ \\
\hline \multicolumn{2}{|c|}{ Kolmogorov-Smimov Z } & 0,428 \\
\hline \multicolumn{2}{|c|}{ Asymp. Sig. (2-tailed) } & 0,993 \\
\hline \multicolumn{3}{|c|}{$\begin{array}{l}\text { a Test distribution is Normal. } \\
\text { b. Calculated from data. }\end{array}$} \\
\hline
\end{tabular}

Berdasarkan hasil pengolahan data dengan menggunakan program SPSS didapat bahwa nilai masing-masing variabel nilai Kolmogorov-Smirnov sebesar 0,428dengan signifikansi $>0,05$ yaitu 0,993 . Hasil tersebut menyatakan bahwa data yang digunakan dalam penelitian ini telah terdistribusi secara normal dan bisa dilanjutkan untuk diteliti lebih lanjut.

\section{Uji Multikolinearitas}

Tabel 4. Uji Multikolinearitas

Uji Multikolinearitas

\begin{tabular}{|l|r|r|}
\hline \multicolumn{3}{|c|}{ Coefficients $^{\mathrm{a}}$} \\
\hline \multirow{2}{*}{ Model } & \multicolumn{2}{|c|}{ Collinearity Statistics } \\
\cline { 2 - 4 } & Tolerance & \multicolumn{1}{c|}{ VIF } \\
\hline LOC & 0,799 & 1,252 \\
\hline II & 0,986 & 1,014 \\
\hline KO & 0,667 & 1,498 \\
\hline ESQ & 0,721 & 1,386 \\
\hline aDependent Varible:DAB & \\
Sumber: Data Primer yang diolah tahm 2019 & \\
\hline
\end{tabular}

Dapat dilihat variabel locus of control, turnover intention, komitmen organisasi dan emotional spiritual quotient (ESQ) memiliki nilai VIF $<10$ dan tolerance $>0,1$. Sehingga dapat dikatakan bahwa tidak terdapat korelasi variabel-variabel bebas antara satu dengan yang lainnya, atau variabel independen pada penelitian ini bebas dari gejala multikolinearitas. 


\section{Uji Heteroskedastisitas}

\begin{tabular}{|c|c|c|c|c|c|c|}
\hline \multicolumn{7}{|c|}{$\begin{array}{r}\text { Tabel 5. Uji Heterosl } \\
\text { Uji Heterokedastisita } \\
\text { Coefficients }^{\mathrm{a}} \\
\end{array}$} \\
\hline \multirow{3}{*}{\multicolumn{2}{|c|}{ Model }} & \multirow{2}{*}{\multicolumn{2}{|c|}{$\begin{array}{l}\text { Unstandardized } \\
\text { Coefficients }\end{array}$}} & \multirow{3}{*}{\begin{tabular}{|c|}
$\begin{array}{c}\text { Standardized } \\
\text { Coefficients }\end{array}$ \\
Beta \\
\end{tabular}} & \multirow[t]{3}{*}{$t$} & \multirow[t]{3}{*}{ Sig. } \\
\hline & & & & & & \\
\hline & & B & Std. Error & & & \\
\hline \multirow{5}{*}{1} & (Constant) & $-3,533$ & 5,147 & & $-0,686$ & 0,497 \\
\hline & LOC & $-0,039$ & 0,068 & $-0,088$ & $-0,568$ & 0,573 \\
\hline & TI & $-0,302$ & 0,170 & $-0,249$ & $-1,776$ & 0,084 \\
\hline & KO & 0,182 & 0,102 & 0,304 & 1,782 & 0,083 \\
\hline & ESQ & 0,056 & 0,048 & 0,193 & 1,175 & 0,247 \\
\hline
\end{tabular}

Berdasarkan tabel diatas dapat dilihat bahwa hasil perhitungan masing-masing variabel menunjukkan bahwa level sig. > 0,05 yaitu 0,573>0,05 untuk varibel locus of control (LOC), untuk variabel turnover intention (TI) sebesar 0,084 >0,05, untuk variabel komitmen organisasi (KO) sebesar 0,083 > 0,05 dan variabel emotional spiritual quotient (ESQ) sebesar 0,247 > 0,05, sehingga penelitian ini bebas dari gejala heterokedastisitas dan layak untuk diteliti.

\section{Analisis Regresi Linear Berganda}

Tabel 6. Analisis Regresi Berganda Coefficients $^{2}$

\begin{tabular}{|c|c|c|c|c|c|c|}
\hline \multirow{2}{*}{\multicolumn{2}{|c|}{ Model }} & \multicolumn{2}{|c|}{$\begin{array}{l}\text { Unstandardized } \\
\text { Coefficients }\end{array}$} & \multirow{2}{*}{\begin{tabular}{|c|}
$\begin{array}{r}\text { Standardized } \\
\text { Coefficients }\end{array}$ \\
Beta \\
\end{tabular}} & \multirow[t]{2}{*}{$\mathrm{T}$} & \multirow[t]{2}{*}{ Sig. } \\
\hline & & $B$ & Std. Error & & & \\
\hline & (Constant) & 30,634 & 10,765 & & 2,846 & 0,007 \\
\hline \multirow{4}{*}{1} & $\mathrm{LOC}$ & $-0,373$ & 0,142 & $-0,398$ & $-2,629$ & 0,012 \\
\hline & II & 1,118 & 0,356 & 0,428 & 3,143 & 0,003 \\
\hline & KO & 0,250 & 0,213 & 0,194 & 1,169 & 0,249 \\
\hline & $\mathrm{ESQ}$ & 0,037 & 0,100 & 0,058 & 0,367 & 0,716 \\
\hline & & & & & & \\
\hline
\end{tabular}

Berdasarkan tabel di atas dapat dianalisis model persamaaan sebagai berikut:

\section{$\mathrm{DAB}=$ 30,634- 0,373 LOC + 1,118TI + 0,250KO + 0,037ESQ+e}

Dari persamaan di atas, dapat dijelaskan bahwa:

a. Nilai konstanta $(\propto)$ sebesar 30,634. Hal ini berarti bahwa jika semua variabel independen bernilai nol, maka nilai dysfunctional audit behavior adalah sebesar konstanta atau 30,634. 
b. Nilai koefisien $\beta$ dari variabel $\mathrm{X}_{1}$ bernilai negatif yaitu - 0,373. Hal ini berarti bahwa setiap peningkatan satu satuan locus of control maka akan menurunkandysfunctional audit behaviour sebesar - 0,373 satuan.

c. Nilai koefisien $\beta$ dari variabel $\mathrm{X}_{2}$ bernilai positif yaitu 1,118 . Hal ini berarti bahwa setiap peningkatan satu satuan turnover intention maka akan meningkatkan dysfunctional audit behaviour sebesar 1,118satuan.

d. Nilai koefisien $\beta$ dari variabel $X_{3}$ bernilai positif yaitu 0,250 . Hal ini berarti bahwa setiap peningkatan satu satuan komitmen organisasi maka akan meningkatkan dysfunctional audit behaviour sebesar0,250 satuan.

e. Nilai koefisien $\beta$ dari variabel $\mathrm{X}_{4}$ bernilai positif yaitu 0,037 . Hal ini berarti bahwa setiap peningkatan satu satuan emotional spiritual quotient (ESQ) terhadap dysfunctional audit behaviour sebesar 0,037satuan.

\section{Koefisien Determinasi $R^{2}$}

Tabel 7. Koefisien Determinasi $\mathbf{R}^{2}$

\begin{tabular}{|l|c|c|c|c|}
\multicolumn{5}{c|}{ CjiAdjusted R $^{2}$} \\
\hline Model & $R$ & R Square & $\begin{array}{c}\text { Adjusted R R } \\
\text { Square }\end{array}$ & Std. Enor of the Estimate \\
\hline 1 & $0,5355^{8}$ & 0,286 & 0,213 & 5,081 \\
\hline a. Predictors: (Constant), ESQ, II, LOC, KO \\
\hline Sumber: Datap primer yang diolah tahum 2019
\end{tabular}

Berdasarkan tabel 7 di atas besarnya Adjusted $R$ Square adalah 0,213. Hal ini mengidentifikasikan bahwa konstribusi variabel independen terhadap variabel dependen adalah sebesar $21,3 \%$, sedangkan 78,7 \% lainnya ditentukan oleh faktor lain di luar model yang tidak diteliti dalam penelitian ini.

\section{b. Uji Regresi Simultan (F-test)}

Tabel 8. Uji Simultan

ANOVA $^{2}$

\begin{tabular}{|l|l|r|r|r|r|r|}
\hline \multicolumn{2}{|l|}{ Iodel } & \multicolumn{1}{|l|}{$\begin{array}{l}\text { Sum of } \\
\text { Squares }\end{array}$} & Df & \multicolumn{1}{c|}{$\begin{array}{c}\text { Mean } \\
\text { Square }\end{array}$} & F & Sig. \\
\hline \multirow{4}{*}{1} & Regression & 403,872 & 4 & 100,968 & 3,910 & $0,009^{\circ}$ \\
\cline { 2 - 8 } & Residual & 1007,037 & 39 & 25,821 & & \\
\cline { 2 - 7 } & Total & 1410,909 & 43 & & & \\
\hline
\end{tabular}

a. Dependent Variable: DAB

b. Predictors: (Constant), ESQ, TI, LOC, KO

Sumber: Pengolahan data primer tahun 2019 


\section{Pengujian Hipotesis 1}

Pengujian hipotesis dilakukan dengan membandingkan thitung dengan nilai tabel. Hipotesis diterima jika $t_{\text {hitung }}>t_{\text {tabel }}$ atau nilai sig. $<0,05$. Nilai tabel pada $\alpha=0,05$ adalah 2,02. Variabel locus of control (LOC) nilai thitung adalah $-2,629$ dan nilai sig. adalah 0,012. Dengan demikian dapat dikatakan bahwa thitung $<\mathrm{t}_{\text {tabel }}$ yaitu $-2,629<2,02$ atau nilai signifikasi $0,012<0,05$. Nilai koefisien $\beta$ dari variabel LOC bernilai negatif yaitu $-0,373$. Hal ini menunjukkan bahwa penelitian ini tidak dapat membuktikan locus of control (LOC) berpengaruh positif signifikan terhadap dysfunctional audit behavior (DAB) dengan demikian hipotesis pertama $\left(\mathbf{H}_{1}\right)$ ditolak.

\section{Pengujian Hipotesis 2}

Pengujian hipotesis dilakukan dengan membandingkan thitung dengan nilai tabel. Hipotesis diterima jika thitung $>t_{\text {tabel }}$ atau nilai sig. $<0,05$. Nilai tabel pada $\alpha=0,05$ adalah 2,02. Variabel turnover intention (TI) nilai thitung adalah 3,143 dan nilai sig. adalah 0,003. Dengan demikian dapat dikatakan bahwa thitung $>t_{\text {tabel }}$ yaitu $3,143>2,02$ atau nilai signifikansi $0,003<0,05$. Nilai koefisien $\beta$ dari variabel TI bernilai positif yaitu 1,118. Hal ini menunjukkan bahwa penelitian ini dapat membuktikan turnover intention (TI) berpengaruh positif signifikan terhadap dysfunctional audit behavior, dengan demikian hipotesis kedua $\left(\mathbf{H}_{2}\right)$ diterima.

\section{Hipotesis 3}

Pengujian hipotesis dilakukan dengan membandingkan $t_{\text {hitung }}$ dengan nilai $t_{t a b e l}$. Hipotesis diterima jika $t_{\text {hitung }}>t_{\text {tabel }}$ atau nilai sig. $<0,05$. Nilai $t_{\text {tabel }}$ pada $\alpha=0,05$ adalah 2,02 . Variabel komitmen organisasi (KO) nilai thitung adalah 1,169 dan nilai sig. adalah 0,249. Dengan demikian dapat dikatakan bahwa thitung $<\mathrm{t}_{\text {tabel }}$ yaitu $1,169<2,02$ atau nilai signifikansi $0,249>0,05$. Nilai koefisien $\beta$ dari variabel komitmen organisasi (KO) bernilai positif yaitu 0,250 . Hal ini menunjukkan bahwa penelitian ini tidak dapat membuktikan komitmen organisasi (KO) berpengaruh signifikan terhadap dysfunctional audit behavior, (DAB) dengan demikian hipotesis ketiga $\left(\mathbf{H}_{3}\right)$ ditolak.

\section{Hipotesis 4}

Pengujian hipotesis dilakukan dengan membandingkan $t_{\text {hitung }}$ dengan nilai $t_{\text {tabel }}$. Hipotesis diterima jika $t_{\text {hitung }}>t_{\text {tabel }}$ atau nilai sig. $<0,05$. Nilai $t_{\text {tabel }}$ pada $\alpha=0,05$ adalah 2,02. Variabel emotional spiritual quotient (ESQ) nilai thitung adalah 0,367 dan nilai sig. adalah 0,716. Dengan demikian dapat dikatakan bahwa thitung $<t_{\text {tabel }}$ yaitu 0,367<2,02atau nilai signifikansi 0,716> 0,05 . Nilai koefisien $\beta$ dari variabel emotional spiritual quotient (ESQ) bernilai positif yaitu 0,037. Hal ini menunjukkan bahwa penelitian ini tidak dapat membuktikan emotional spiritual quotient (ESQ) berpengaruh signifikan terhadap dysfunctional audit behavior, (DAB) dengan demikian hipotesis keempat $\left(\mathbf{H}_{\mathbf{4}}\right)$ ditolak.

\section{Pembahasan Hipotesis}

\section{Pengaruh Locus of ControlTerhadap Dysfunctional Audit Behavior}

Berdasarkan hasil analisis statistik dalam penelitian ini, ditemukan bahwa hipotesis pertama ditolak. Pernyataan ini berdasarkan nilai koefisien locus of control (LOC) sebesar $-0,373$ dan nilai signifikansi pengalaman auditor sebesar 0,012 lebih kecil dari signifikansi $(\alpha=0,05)$ artinya jika dilihat dari nilai koefisien locus of control yang menunjukkan arah negatif maka dapat disimpulkan bahwa locus of control berpengaruh negatif terhadap dysfunctional audit behavior sehingga hipotesis pertama dalam penelitian ini ditolak. 


\section{Pembahasan \\ Pengaruh Locus of Control terhadap Dysfunctional Audit Behavior}

Sesuai teori atribusi seseorang melakukan dysfunctional audit behavior dalam locus of control disesbabkan oleh internal locus of control dan eksternal locus of control. Berdasarkan hasil penelitian yang telah dilakukan, jawaban responden yang kurang baik itu umumnya terdapat pada eksternal locus of control. Dapat dikatakan bahwa dalam penelitian tersebut responden cendrung memiliki internal locus of control. Seorang individu dengan internal locus of control lebih meyakini kemampuan sendiri daripada situasi atau lingkungan yang menguntungkan, sedangkan auditor yang memiliki eksternal locus of control sering menggantungkan harapannya pada orang lain, hidup mereka cenderung dikendalikan oleh kekuatan di luar diri mereka (seperti keberuntungan, nasib atau takdir) yang membuat mereka sering mencari kondisi yang akan mendatangkan keuntungkan bagi dirinya.

Pada saat mereka merasa tidak mampu untuk mendapatkan dukungan dari pihak lain, mereka memilih potensi untuk mencoba memanipulasi rekan kerja atau pun objek lainnya, sehingga akan menimbulkan terjadinya dysfunctional audit behavior. Auditor yang memiliki internal locus of control dapat menekan perilaku dysfunnctionall audit behavior karena cara pandang mereka terhadap suatu kesuksesan tersebut dipengruhi oleh diri sendiri tidak melalui faktor luar.

Hasil penelitian ini selaras dengan hasil penelitian Setyaningrim (2014) dan penelitian Maryanti (2005) yang menunjukkan bahwa locus of control tidak berpengaruh terhadap dysfunctional audit behavior. Hasil penelitian ini tidak sejalan dengan penelitian Wahyudi, E (2013) dan penelitian Halim, A (2016) yang menyatakan bahwa locus of control memiliki pengaruh signifikan positif terhadap dysfunctional audit behavior.

\section{Pengaruh Turnover IntentionTerhadap Dysfunctional Audit Behavior}

Hipotesis 2 pada penelitian ini adalah turnover intention terhadap dysfunctional audit behavior. Berdasarkan hasil analisis statistik dalam penelitian ini, ditemukan bahwa hipotesis kedua diterima. Pernyataan ini berdasarkan nilai koefisien turnover intention (TI) sebesar 1,118 dan nilai signifikansi kompetensi sebesar 0,003 lebih kecil dari signifikansi $(\alpha=0,05)$ artinya jika dilihat dari nilai koefisien kompetensi yang menunjukkan arah positif maka dapat disimpulkan bahwa turnover intention berpengaruh positif signifikan terhadap dysfunctional audit behavior sehingga hipotesis pertama dalam penelitian ini diterima.

Berdasarkan teori atribusi menjelaskan seorang auditor yang memiliki keinginan berhenti kerja (turnover intention) lebih berpeluang dalam melakukan dysfungsional audit behaviour karena menurunnya tingkat ketakutan yang ada dalam dirinya terhadap sanksi yang didapatkan saat prilaku tersebut terdeteksi melanggar standar audit. Individu yang berniat meninggalkan pekerjaan tidak begitu peduli dengan dampak buruk dari penyimpangan perilaku terhadap penilaian kinerja dan promosi.

Hasil penelitian ini sejalan dengan penelitian Oktaviani, W (2017) membuktikan bahwa turnover intention memiliki pengaruh postitif pada dysfunctional audit behavior. Auditor yang memiliki keinginan tinggi untuk untuk berhenti bekerja (turnover intention) akan lebih bepeluang untuk melakukan dysfunctional audit behavior. Begitupun dengan penelitian Pujaningrum (2012) menjelaskan bahwa auditor yang memiliki keinginan untuk berhenti bekerja (turnover intention) lebih mungkin terlibat dalam perilaku disfungsional, karena penurunan rasa takut dari kondisi yang terjadi bila hal tersebut terdeteksi. 
Penelitian ini juga sejalan dengan penelitian Nasution, I (2013) dan Hadi, S (2014) menjelaskan bahwa auditor yang memiliki keinginan untuk berhenti bekerja (turnover intention) berpengaruh positif terhadap dysfungsional audit behavior. Auditor yang berkeinginan untuk keluar dari organisasinya, lebih cenderung tidak peduli atas dampak perilaku yang dilakukannya. Individu yang memiliki keinginan untuk meninggalkan perusahaan menjadi lebih kecil kemungkinannya untuk khawatir dengan dampak potensial dari dysfunctional audit behavior, dengan demikian auditor yang memiliki keinginan yang tinggi untuk meninggalkan pekerjaannya, mungkin lebih menerima dysfunctional audit behavior.

\section{Pengaruh Komitmen Organisasiterhadap Dysfunctional Audit Behavior}

Hipotesis ketiga dalam penelitian ini adalah komitmen organisasi berpengaruh negatif terhadap dysfunctional audit behavior. Berdasarkan hasil analisis statistik dalam penelitian ini, ditemukan bahwa hipotesis ketiga ditolak. Pernyataan ini berdasarkan nilai koefisien komitmen organisasi sebesar 0,250 dan nilai signifikansi komitmen organisasi sebesar 0,249 lebih besar dari signifikansi $(\alpha=0,05)$ artinya jika dilihat dari nilai koefisien komitmen organisasi yang menunjukkan arah positif maka dapat disimpulkan bahwa komitmen organisasi tidak berpengaruh signifikan terhadap dysfunctional audit behavior sehingga hipotesis ketiga dalam penelitian ini ditolak.

Penelitian ini menemukan bahwa keinginan untuk komitmen organisasi tidak berpengaruh signifikan terhadap dysfunctional audit behavior pada auditor BPK RI perwakilan Sumatera Barat. Hasil penelitian ini sama dengan hasil yang ditemukan Wahyudi, E (2013) yang menemukan bahwa komitmen organisasi tidak mempunyai pengaruh yang signifikan terhadap dysfunctional audit behavior yang dapat menurunkan kualitas audit, komitmen organisasi bukan menjadi pertimbangan auditor dalam melakukan dysfungsional audit behaviour, auditor yang memiliki komitmen organisasi yang tinggi tidak menunjukkan kecenderungan untuk menerima perilaku penyimpangan audit sebagaimana yang dihipotesiskan.

Teori atribusi menjelaskan tiga dimensi komitmen organisasi yang mempengaruhi perilaku seseorang dalam suatu organisasi yaitu karena faktor komitmen afektif (ingin melakukannya), komitmen kontinu (menyadari bahwa dia akan rugi ketika tidak melakukannya), dan komitmen normatif (merasa harus melakukannya). Karyawan yang mempunyai komitmen lebih tinggi akan menunjukkan loyalitas yang besar kepada perusahaan dimana mereka bekerja dibanding karyawan yang memiliki komitmen yang lebih rendah, sehingga ada kecenderungan pula bahwa auditor yang memiliki komitmen yang tinggi akan menerima saran-saran yang diberikan oleh atasan meskipun atasan dapat mendorong terjadinya perilaku disfungsi audit seperti misalnya premature sign off maupun underreporting time tidak terbukti. Secara teoritis komitmen organisasi terdiri dari 3 bentuk komitmen yaitu komitmen afektif, normative dan continue.

Berkaitan dengan perilaku negatif fungsi seperti perilaku penerimaan disfungsi audit terdapat kondisi yang tidak searah antar komitmen continue dan komitmen afektif dan normative. Dalam komitmen continue terkandung makna bahwa keinginan auditor untuk bekerja didalam audit dapat mendorong mereka untuk menerima perilaku disfungsi, namun di sisi lain komitmen afektif yang merupakan cerminan perasaan dari auditor untuk menjunjung tinggi nama instansi justru dapat menolak untuk menerima perilaku disfungsi dengan pertimbangan tertentu.

Dengan kata lain komitmen organisasi (afektif) yang tinggi akan menciptakan keinginan untuk meningkatkan kinerja audit, sedangkan kualitas tempat auditor berkerja dapat ditunjukkan dengan pelaksanaan prosedur yang benar yang dilakukan oleh auditornya. Berdasarkan 
penjelasan di atas, semakin tinggi komitmen organisasi tidak berdampak pada terjadinya praktek dysfunctional audit behavior. Maka, dapat disimpulkan bahwa tidak adanya pengaruh antara variabel komitmen organisasi dan dysfunctional audit behavior. Hasil penelitian ini tidak sesuai dengan penelitian yang dilakukan oleh Halim, A (2016) yang mendapatkan hasil penelitian bahwa komitmen organisasi berpengaruh negative terhadap dysfunctional audit behafior.

\section{Pengaruh Emotional Spiritual QuotientTerhadap Dysfunctional Audit Behavior}

Hipotesis keempat dalam penelitian ini adalah emotional spiritual quotient berpengaruh negatif terhadap dysfunctional audit behavior. Berdasarkan hasil analisis statistik menggunakan program SPPS dalam penelitian ini, ditemukan bahwa hipotesis keempat ditolak. Pernyataan ini berdasarkan nilai koefisien emotional spiritual quotient (ESQ) sebesar 0,037 dan nilai signifikansi emotional spiritual quotient sebesar 0,716 lebih besar dari signifikansi $(\alpha=0,05)$ artinya jika dilihat dari nilai koefisien kompetensi yang menunjukkan arah positif maka dapat disimpulkan bahwa emotional spiritual quotient tidak berpengaruh signifikan terhadap dysfunctional audit behavior sehingga hipotesis keempat dalam penelitian ini ditolak.

Teori atribusi menyatakan penyebab seseorang berprilaku disfungsional dalam ESQ karena ketiga kecerdasan tersebut tidak seimbang. Hasil dari penelitian ini menyatakan bahwa ESQ tidak berpengaruh secara signifikan negatif terhadap dysfunctional audit behavior yang diakibatkan oleh semakin tingginya ESQ ada kemungkinan rasa empati dari auditor terhadap klien / perusahaannya sendiri sehingga ada kemungkinan bahwa auditor akan melakukan disfunctional audit behaviour. Hasil penelitian ini tidak sama dengan penelitian yang dilakukan oleh Dalli, N, dkk (2017) dan Oktaviani, W (2017) menyatakan bahwa penerimaan berpengaruh negatif terhadap penerimaan dysfunctional audit behavior

\section{KESIMPULAN, KETERBATASAN, SARAN \\ Kesimpulan}

Berdasarkan hasil temuan penelitian dan pengujian hipotesis yang telah dilakukan dapat disimpulkan bahwa:

1. Locus of control tidak berpengaruh signifikan terhadap dysfunctional audit behavior.

2. Turnover intention berpengaruh signifikan positif terhadap dysfunctional audit behavior, auditor yang memiliki keinginan berhenti kerja (turnover intention) lebih berpeluang dalam melakukan dysfungsional audit behaviour karena menurunnya tingkat ketakutan yang ada dalam dirinya terhadap sanksi yang didapatkan saat prilaku tersebut terdeteksi melanggar standar audit.

3. Komitmen organisasi tidak berpengaruh signifikan terhadap dysfunctional audit behavior. Komitmen organisasi membuat individu lebih taat terhadap peraturan organisasi dibandingkan standar audit, serta auditor yang memiliki komitmen organisasi yang tinggi cenderung mengikuti perintah atasan, yang mungkin saja melenceng dari standar audit yang berlaku.

4. ESQ tidak berpengaruh secara signifikan negative terhadap dysfunctional audit behavior yang diakibatkan oleh semakin tingginya ESQ ada kemungkinan rasa empati dari auditor terhadap klien sehingga seorang auditor akan melakukan dysfunctional audit behaviour.

\section{Keterbatasan Penelitian}

Peneliti telah berusaha merancang dan mengembangkan penelitian sedemikian rupa, namun masih terdapat beberapa keterbatsan dalam penelitian ini yang masih perlu direvisi bagi peneliti selanjutnya, yaitu antara lain: 
1. Sampel yang digunakan dalam penelitian ini hanya 50 auditor yang bekerja di BPK, yang masih terbilang sedikit untuk menjadi sampel dalam meneliti.

2. Nilai Adjusted $R^{2}$ yang rendah yaitu sebesar $21,3 \%$ menunjukkan bahwa masih banyak variabel lain yang memiliki kontribusi besar dalam mempengaruhi disfunctional audit behavior.

\section{Saran}

Berdasarkan keterbatasan yang ada pada penelitian ini, maka saran dari peneliti atas penelitian ini adalah:

1. Bagi peneliti selanjutnya hendaknya melakukan penelitian pada auditor KAP kecil hingga besar, dan meneliti auditor BPK secara keseluruhan sehinga sampel penelitian lebih banyak agar hasil yang diperoleh lebih berkualitas.

2. Bagi peneliti selanjutnya agar menambah variabel lain yang diidentifikasi dapat mempengaruhi disfunctional audit behavior karena rendahnya nilai Adjusted $R^{2}$ yang dihasilkan dalam penelitian ini. Variabel lain, seperti tekanan anggaran, waktu audit dan variabel lainnya.

\section{DAFTAR PUSTAKA}

Basudewa, Dewa Gede Agung., Ni Kt. Lely Aryani Merkusiwati. 2015. Pengaruh Locus Of Control, Komitmen Organisasi, Kinerja Auditor, dan Turnover Intention pada Perilaku Menyimpang Dalam Audit. ISSN: 2303-1018 EJurnal Akuntansi Universitas Udayana Vol.13.3 Desember (2015): 944-972

Dalli, Nasrullah ,.dkk . 2017. Pengaruh Kecerdasan Intelektual, Emosional, dan Spiritual (ESQ) dan Lokus Pengendalian (Locus Of Control) Terhadap Penerimaan Prilaku disfungsional Audit (Studi Pada Badan Pemeriksa Keuangan Perwakilan Sulawesi Tenggara). Jurnal Akuntansi dan Keuangan Volime II.

Donnelly, P. D., Quirin J. J., dan O'Bryan D. 2003. Auditor Acceptance of Dysfunctional Audit Behavior: An Explanatory Model Using Auditor's Personal Caracteristics, Behavioral Research In Accounting. Vol. 15. 87- 110.

Hadi, Syamsul. 2014. Pengaruh Karakteristik Personal dan Faktor Situasional Dalam Penerimaan Perlakuan Disfungsional. EKBISI, Vol. IX, No. 1. ISSN:1907-9109.

Halim, Abdul. 2016. Pengaruh Locus of Control, Komitmen Organisasi, Gaya Kepemimpinan, dan Emotional Spiritual Quotient Terhadap Penerimaan Auditor Atas Dysfunctional Audit Behavior. Skripsi. Tidak Diterbitkan.

Harini, Dwi, Agus Wahyudin dan Indah Anisykurlillah. 2010. Analisis Penerimaan Auditor atas Dysfunctional Audit Behaviour: Sebuah Pendekatan Karakteristik Personal Auditor. Simposium Nasional Akuntansi XIII Purwokerto.

Hasibuan, S.P. Malayu. 2007. Manajemen Dasar, Pengertian dan Masalah. Bumi Aksara: Jakarta.

Havel, Nadya. 2017. Pengaruh Karakteristik Personal Auditor dan Emosional Spiritual Quotient (ESQ) Terhadap Penerimaan Perilaku Disfungsional Audit. JOM Fekon, Vol. 4 No. 1.

Husna, Lina Febrina. 2012. Analisis Pengaruh Karakteristik Personal Auditor Terhadap Penerimaan Auditor Atas Disfungsional Audit Behavior (Studi Empiris Pada Kantor Akuntan Publik di Jawa Tengah dan Yogyakarta). Skripsi. Universitas Diponegoro. 
Irawati, Yuke., Petronila, Thio, Anastasia., dan Mukhlasin. 2005. Hubungan Karakteristik Personal Auditor Terhadap Tingkat Penerimaan Penyimpangan Perilaku Dalam Audit. Simposium Nasional Akuntansi VIII. 929-940.

Nasution, Istianah. 2013. Pengaruh Karateristik Personal Auditor, Etika Audit dan Pengalaman Auditor Terhadap Tingkat Penyimpangan Perilaku Dalam Audit. Skripsi. Tidak Dipublikasi.

Oktaviani, Wulan. 2017. Pengaruh Personalitas Auditor dan Etika Profesi Terhadap Penerimaan Perilaku Audit Disfungsional. JOM Fekon, Vol. 4 No 1.

Sugiyono. 2014. Metode Penelitian Kuantitatif Kualitatif dan R\&D. Bandung : Alfabeta.

Trisnaningsih, S., 2003. Pengaruh Komitmen terhadap Kepuasan Kerja Auditor: Motivasi sebagai Variabel Intervening (Studi Empiis pada Kantor Akuntansi Publik di Jawa Timur). Jurnal Riset Akuntansi Indonesia, 96). 199-216.

Wahyudi, Eko. 2013. Pengaruh Locus of Control, Kinerja, Komitmen Organisasi, dan Turnover Intention Terhadap Penyimpangan Perilaku Dalam Audit (Studi Empiris pada Kantor Akuntan Publik di Jakarta Selatan). Skripsi Tidak Diterbitkan.

Wijayanti, Gersontan Lewi. 2012. Peran Kecerdasan Emosional dan Kecerdasan Spritual dalam Meningkatkan Kinerja Auditor. Jurnal Ilmiah Mahasiswa Akuntansi, VOL.1 NO.2. 